\title{
Didactic variable in Russian students' ulterior motivation for second language learning
}

\author{
Karina Melezhik ${ }^{1, *}$, Aleksandr Petrenko ${ }^{1}$, and Nataliya Khlybova ${ }^{1}$ \\ ${ }^{1}$ V.I. Vernadsky Crimean Federal University, Vernadsky Avenue 4, 35000, Simferopol, Russian Federation
}

\begin{abstract}
The purpose of the article is to identify factors characterizing interdependence between the English proficiency level and motivation in the conventionally organized Russian university English classroom where all students are treated as having similar learning profiles. It is claimed that deficiency of classroom motivation accounts for the students' negative attitude to and low effectiveness of university English teaching. The author proposes to apply Brousseau's concept of didactical situations, environment and variables as a way of revising the content of the motivational spectrum of the English learner. An experiment for studying the impact of ulterior motivation variables on an individual English proficiency level was carried out in a group of 100 graduate students of Crimean Federal University with the aim to find out the students' individual ulterior motives explaining variability of attitudes towards English as a subject of the curriculum. The findings of the experiment proved that the students' motivational preferences didn't meet motivational criteria of their teachers and curriculum. The students' self-assessment of their English proficiency showed a significant correlation among English proficiency, individual ulterior motivation variables and individual goals connected with their plans for the future. The main conclusion is that the task of learning transnational English should be viewed as a sequence of didactical situations predetermined by a set of didactical motivation variables. To find out ulterior didactical motivation variables, the teacher should identify the student's types of potential milieu and choose a succession of appropriate didactical situations.
\end{abstract}

\section{Introduction}

In the era of globalization of all spheres of social life the scope of ethnically diverse interpersonal contacts has been dramatically increasing and, consequently, transnational communication has required the knowledge of an additional, foreign language as a contact tool. Until recently, the motivation to learn foreign languages, viewed as potential contact tools, has been mainly based on the idea of their social value as a prerequisite of the general cultural and socio-economic progress of the society in which a personality is being formed because it provides immediate access to the spiritual wealth of another country and serves as an attribute of a modern highly educated person [1]. The truism is still popular among second language teachers that a student who has no motivation will not be able to master a new language, therefore the problem of motivating students to learn a foreign language is most important in education [2].

It is a plain fact that the scope of motivation is variegated and there is no unanimous understanding of the multi-faceted nature of the concept that inspires scholars to continue studying it [3]. Canadian researcher R. C. Gardner, who laid foundations of the motivation theory, defines it as "the extent to which the individual works or strives to learn the language because of a desire to do so and the satisfaction experienced in this activity". Gardner's definition offers three main components: a) an effort expended to achieve the goal; b) a desire, to learn the foreign language, and c) satisfaction accompanying achievement of the goal of acquiring the language [4].

Motivation is considered the main driving force in learning a foreign language and functioning as a gatekeeper to the subjective world of a person. Many sociolingusts and teachers claim that the major types of motivation for students' learning English are instrumental and integrative motives focusing on cultural education [5].

Russian scholar I. Zimnyaya argues that the individual's worldview is determined not only by socially significant factors, but also by internal motives, which, in turn, depend on the conditions of existence, moral and political attitudes, communicative objectives and deeply rooted interests [6].

On the whole, Russian researchers have limited specific individual factors of educational motivation to personality characteristics of the learner (gender, intellectual maturity, ability to assess teachers and their academic potential, positive and negative ways of the pedagogical process, specifics of the foreign language as an academic subject [7]

We cannot but agree with British sociolinguist $M$. Lamb who maintains that any good teacher is, by definition, a motivator of learning, however a motivational dimension in teaching is distinct from a motivational dimension in 'good teaching', because

\footnotetext{
* Corresponding author: author@e-mail.org
} 
students should be motivated to achieve their goals as efficiently as possible [8].

Accordingly, the student's motivation in mastering a foreign language has been treated as a complex and dynamic phenomenon identified in terms of two factors: a) communication needs and student's motivational preferences and $b$ ) attitude to the foreign language [9].

Evidently, these factors are closely associated with different types of motivation, as well as with different sources and contexts of motivation. Thus, instrumental motivation operates in the context where the foreign language offers educational and/or economic opportunities, and it is effective if it works for the most optimal use of the result. Integrative motivation includes an interest in the study of the people and/or culture of the language with the aim of being accepted into a certain community.

Intrinsic motivation includes maintaining interest and personal involvement in learning activities, achieving success, gaining competence and setting new goals. Some authors note that internal motives may be associated with the content of educational material, with cognitive activity aimed at identifying cause-and-effect relationships in the studied educational material [10].

\section{Problem Statement}

Over the past two or three decades, the content of intrinsic or internal motivation for learning a foreign language has greatly changed in the Russian education system as a result of social, political and economic innovations. Socially significant and intellectually cognitive motives (access to foreign language information in the Internet space, the ability to learn foreign culture and mentality [11]) have largely given way to such internal motivation factors as the desire to move up the career ladder [12], to study and work abroad, to cooperate with foreign partners, etc. [9].

Since the main foreign language in the Russian education system is English, its global recognition as a universal contact tool for transnational communication has become the decisive external motivational factor. Due to the polycentric structure of global English employed in transnational communication it has stopped to be identified with any particular national culture or any particular ethnic mentality. However, in Russian education system British English is still accepted as a target learning model, which presupposes familiarizing with elements of British culture and mentality. This fact makes it necessary to find ways to revise the content of the motivational spectrum of the learner.

We propose to consider the motivation for foreign language learning from the point of view of $G$. Brousseau's theory of didactical situations. Like any other instructional process, language learning is a sequence of didactical situations which are defined by $\mathrm{G}$. Brousseau as projects organized to cause students to appropriate some reference knowledge. In a didactical situation the teacher sets up the students to accept the challenge of an engaging and instructive situation and prepares them by clearing out the situation parameters in advance: conditions, rules, goal, and above all the criterion for success. S/he challenges students to do it without his/her help on their own responsibility [13].

In Brousseau's theory, knowledge is a property of a system constituted by interaction of a subject and an environment, a "milieu". Learning occurs through this interaction: the subject acts within and receives feedback from the milieu.

With a learning task, the teacher determines an optimal milieu including all the elements the student will deal with and hence the student's potential for learning. Key aspect of a didactical situation is the choice of didactical variables - values which can be criteria for success or failure of the task and cause for the student to learn.

The task of learning a foreign language in a sequence of didactical situations is predetermined by a set of didactical motivation variables. Teachers can be unaware of students' ulterior motivation variables though ulterior variables might affect results of teaching no less than extrinsic motivation variables. A combination of different didactical variables contributes to the didactical situation, and the teacher should identify both the student's current and future types of potential milieu, hence prognosticate his/her perspectives for learning and then choose a succession of appropriate combinations of didactical variables.

\section{Research Questions}

Every language teacher knows that motivation as well as attitude to and interest in the subject are crucial variables of the classroom environment where any two students may look alike or have similar abilities, but their academic behavior could be totally different [14]. It is indispensable to formulate and answer several key questions that will help teachers analyze didactical variables in the contexts of globalization as they are indispensable for preparing students to use contact English in would-be transnational communication.

Question 1. Do their students have to be familiarized with elements of British culture and mentality if they plan to speak contact English, for example, in Turkey or Egypt, Nordic countries or Southeast Asia?

Question 2. To what extent do the students' motivational preferences meet motivational criteria of their teachers and curricula?

Question 3. What is the realistic scope of motivation to be relied on in the process of teaching students contact English of transnational communication?

Question 4. What is the impact of the students' ulterior motivation as a didactic factor in teaching basic skills of transnational English language communication?

\section{Purpose of the Study}

The purpose of this article is to investigate the interdependence of ulterior motivational variability and the levels of mastering English as observed in the English language classroom milieu. 


\section{Research Method}

To determine the interdependence between the English proficiency level and particular types of motivation an experiment was carried out in which 100 graduate students of socio-economic and humanitarian departments of V.I. Vernadsky Crimean Federal University took part, including 50 male students and 50 female students. The average age of respondents was 21 years. The experiment was carried out in two stages.

At the first stage the current state of the students' motivation and attitude to English was studied in a series of half-structured interviews that pursued a twofold objective: 1) to find out the variability of experience they have accumulated in learning and using English; 2) to clarify the respondents' motivational variability of attitudes towards English both as a transnational communication tool and a subject of the curriculum.

At the second stage each student was asked 1) to selfassess his/her English proficiency level using the selfassessment grid of the Common European Framework of Reference for Languages (CEFR). Then a semistructured interview followed with the objective: 1) to make students share their plans for using English after graduation from the University and 2) to find out their individual ulterior motivation for acquiring English as a contact language in connection with the plans they may have for the future.

\section{Findings}

\section{Stage 1.}

Every student received a questionnaire in which there were 8 questions. The individual answers were analyzed to add up into a general picture of the group variation of English learner and user experience and motivational trends.

Question 1. How many years have you been learning English at school and university?

Answers: 12 years $-58 \%, 9$ years $-42 \%$.

Question 2. Can you say that you received basic knowledge of the English language at school and university classes?

Answers: Yes $-20 \%$ of male students and $6 \%$ of female students; No $-64 \%$ of male students and $70 \%$ of female students; No answer - $16 \%$ of male students and $24 \%$ of female students.

Question 3. Can you assess the effectiveness of your university classes in mastering spoken English on a fourpoint scale (A - very effective; $\mathrm{B}$ - fairly effective; $\mathrm{C}$ hardly effective; D - ineffectual)?

Answers: A (none); B (20\% of male students and 6\% of female students); C (64\% of male students and $70 \%$ of female students); D (16\% of male students and $24 \%$ of female students).

Question 4. Can you assess the effectiveness of your university classes in mastering special English on a fourpoint scale (A - very effective; $\mathrm{B}$ - fairly effective; $\mathrm{C}$ hardly effective; D - ineffectual)?
Answers: A (none); B (72\% of male students and $78 \%$ of female students); C ( $28 \%$ of male students and $22 \%$ of female students); D (none).

Question 5. Have you ever studied English elsewhere in addition to school/university in language courses, individual lessons, on your own?

Answers: $52 \%$ of female students have studied English with a private teacher, 24\% - independently, $18 \%$ - in a group at language courses, $6 \%$ have studied English only at school and university. $50 \%$ of male students have studied English independently, 30\% - in a group at language courses, 20\% have studied English only at school and university. None have studied English with a private teacher.

Question 6. Do you use English on the Internet (in social networks, in personal correspondence, to search for general information, to search for special information)?

Answers: $70 \%$ of male students and $78 \%$ of female students use English on the Internet, including 36\% of male students and $42 \%$ of female students for personal correspondence, $60 \%$ of male students and $74 \%$ of female students for search of general information, $52 \%$ of male students and $58 \%$ of female students for search of special information. Communicate with Englishspeaking friends on the Internet (e-mail, Skype, Facebook, Twitter, etc.) $20 \%$ of male students and $36 \%$ of female students. Participate in blogs and/or forums $25 \%$ of male students and $32 \%$ of female students. Play internet games $20 \%$ of male students and $16 \%$ of female students. Watch YouTube shows, video clips, etc. 20\% of male students and $18 \%$ of female students.

Question 7. Did you use English on a foreign trip (on a tour, while working or studying abroad)?

Answers: $40 \%$ of male students and $24 \%$ of female students used English on a trip to another country. Of this number $16 \%$ of male students and $12 \%$ of female students used to work abroad during summer holidays.

Question 8. Have you taken the TOEFL or IELTS qualifying exams?

Answers: Yes $-10 \%$ of male students and $16 \%$ of female students. No $-74 \%$ of male students and $60 \%$ of female students. No answer $-16 \%$ of male students and $24 \%$ of female students.

It is not a surprise that all English classroom settings of a Russian university have been conventionally organized as if all students were characterized by similar ability and proficiency levels. A striking surprise in the area of university language teaching is that students in the same classroom display significantly variegated learning profiles resulting from different length and mode of language learning and language exposure. What is obviously neglected in the academic contexts is the fact that many if not all students belong in the "digital generation", i.e. their interest in learning English is far beyond the limits of the classroom and concerns using English on the Internet, in social networks, in personal correspondence and search for information, communication with English-speaking friends, watching video shows, etc.

Deficiency of classroom motivation accounts for relatively low assessment of the effectiveness of 
university classes in mastering special English or mostly indifferent or partly negative attitude to the effectiveness of university classes in mastering special English. It's a reason for serious concern that $16 \%$ of male students and $24 \%$ of female students state they did not receive basic knowledge of the English language at school and university classes. These factors require recognition of individual needs and targets of students, individual styles and potentialities of learning English.

\section{Stage 2.}

Students were asked to assess their level of English proficiency on the scale of the ESP classroom students. Students are recommended to start by finding where they are and identify personal objectives to be achieved with the help of this Manual.

The Common European Framework (CEF) describes what a learner can do at six specific levels: Basic User (A1 and A2); Independent User (B1 and B2); Proficient User ( $\mathrm{C} 1$ and $\mathrm{C} 2$ ). These levels match general concepts of basic, intermediate, and advanced and are often referred to as the Global Scale [15].

\section{Basic A1}

- Can understand and use familiar everyday expressions and very basic phrases aimed at the satisfaction of needs of a concrete type.

- Can introduce him/herself and others and can ask and answer questions about personal details such as where he/she lives, people he/she knows and things s/he has.

- Can interact in a simple way provided the other person talks slowly and clearly and is prepared to help.

Answers: 0\% of male and female students.

\section{Basic A2}

- Can understand sentences and frequently used expressions related to areas of most immediate relevance (e.g. very basic personal and family information, shopping, local geography, employment).

- Can communicate in simple and routine tasks requiring a simple and direct exchange of information on familiar and routine matters.

- Can describe in simple terms aspects of his/her background, immediate environment and matters in areas of immediate need.

Answers: $16 \%$ of male and $22 \%$ of female students.

\section{Independent B1}

- Can understand the main points of clear standard input on familiar matters regularly encountered in work, school, leisure, etc.

- Can deal with most situations likely to arise while travelling in an area where the language is spoken.

- Can produce simple connected text on topics which are familiar or of personal interest.

- Can describe experiences and events, dreams, hopes and ambitions and briefly give reasons and explanations for opinions and plans.

Answers: $44 \%$ of male and $36 \%$ of female students.

\section{Independent B2}

- Can understand the main ideas of complex text on both concrete and abstract topics, including technical discussions in his/her field of specialization.
- Can interact with a degree of fluency and spontaneity that makes regular interaction with native speakers quite possible without strain for either party.

- Can produce clear, detailed text on a wide range of subjects and explain a viewpoint on a topical issue giving the advantages and disadvantages of various options.

Answers: $22 \%$ of male and $26 \%$ of female students.

\section{Proficient C1}

- Can understand a wide range of demanding, longer texts, and recognize implicit meaning.

- Can express him/herself fluently and spontaneously without much obvious searching for expressions.

- Can use language flexibly and effectively for social, academic and professional purposes.

- Can produce clear, well-structured, detailed text on complex subjects, showing controlled use of organizational patterns, connectors and cohesive devices.

Answers: $18 \%$ of male and $16 \%$ of female students.

\section{Proficient C2}

- Can understand with ease virtually everything heard or read.

- Can summarize information from different spoken and written sources, reconstructing arguments and accounts in a coherent presentation.

- Can express him/herself spontaneously, very fluently and precisely, differentiating finer shades of meaning even in more complex situations.

Answers: 0\% of male and female students.

Basic level A1 and Proficient level C2 were let out of the self-assessment for obvious reasons: even the poorest learners' proficiency was beyond A1 and the brightest learners didn't dare claim C2 level proficiency of using English flexibly and effectively for social, academic and professional purposes in virtually all situations. Basic A2 level was marked by $19 \%$ of all students, Independent B1 - by $40 \%$, Independent B 2 - by $24 \%$, Proficient C1 by $17 \%$. As it is, as many as $19 \%$ of all students don't meet official requirements of the English language curriculum and as few as $17 \%$ claim to be able to safely pass TOEFL or IELTS exams.

How important is English for the students' plans after graduation from the University and what is their individual ulterior motivation for using English as a contact language in connection with the plans they may have for the future?

Summing up the data received in the semi-structured interviews we have found out that the students will need English as a contact language:

1) to be mobile in the modern world $-54 \%$ of male and $42 \%$ of female students;

2 ) to increase their knowledge / intellectual abilities $54 \%$ of male and $42 \%$ of female students. These students have no definite plans for the future and the knowledge of English has an obviously symbolic value of intellectual and partially instrumental kind because it enhances hypothetical chances of travelling around the world.

$46 \%$ of male and $58 \%$ of female students make plans to move abroad for permanent residence. This is their individual ulterior motivation and they were reluctant to discuss it in the presence of other students. Many 
respondents of this number think they will need English as a contact language:

a) to get married abroad $-34 \%$ of male and $32 \%$ of female students;

b) to find a better paid job abroad $-34 \%$ of male and $28 \%$ of female students;

c) to take TOFEL/IELTS exams and continue education abroad $-20 \%$ of male and $16 \%$ of female students. Many students combined answers a), b) and c).

$12 \%$ of male and $26 \%$ of female students did not want to specify for confidential reasons in what contexts of transnational communication they will need contact English while living abroad.

The findings reveal that pragmatic ulterior motives for acquiring English proficiency are mostly integrative and instrumental. There is hardly any symbolic intellectual value about this kind of individual motivation as it is based on personal effort, expectancy of success, and self-estimation of internally determined ability for learning the contact language. Our findings also prove that female students are more motivated than their male fellow students are. Similarly, students demonstrating proficiency levels B2 and $\mathrm{C} 1$ students were more motivated than were students demonstrating proficiency levels A2 and B1.

\section{Conclusion}

Transnational English as a universal contact tool is no longer identified with any national culture or ethnic mentality due to its polycentric nature though in the Russian education system familiarizing with elements of British culture and mentality is still accepted as an intellectual factor of instrumental and integrative motivation to learn English.

It is proposed to apply G. Brousseau's concept of didactical situations, environment and variables as a way of revising the content of the motivational spectrum of the English learner. The task of learning transnational English is viewed as a sequence of didactical situations predetermined by a set of didactical motivation variables. To find out ulterior didactical motivation variables, the teacher should identify the student's types of potential milieu and choose a succession of appropriate didactical situations.

The interdependence between the English proficiency level and motivation variables is neglected in the conventionally organized university English classroom where students are assigned similar ability and proficiency levels though they may obviously display different learning profiles. Deficiency of classroom motivation accounts for the students' negative or even disparaging attitude to the effectiveness of university English classes where individual motivation variables of learning English are plainly discarded.

We propose a two-stage procedure to overcome organizational conventionality of the university English classroom aiming at disclosure of the students' individual ulterior motivation variables which otherwise may stay beyond the teacher's attention. The first stage is to find out the students' realistic individual motives, to clarify their variability of attitudes towards the instruction components and English as a subject of the curriculum. It is obvious that the students' motivational preferences don't meet motivational criteria of their teachers and curriculum.

At the second stage students are asked to self-assess their English proficiency and disclose their individual ulterior motivation for acquiring English as a contact language in connection with the plans they may have for the future.

An experimental survey of graduate students' pragmatic ulterior motives for acquiring English proves that $52 \%$ of all respondents exclusively rely on their personal efforts for the purpose of acquiring English as a contact tool of integrative and instrumental motivation. There is hardly any symbolic intellectual value about this kind of individual motivation as it is based on personal effort, expectancy of success, and self-estimation of internally determined ability for learning the contact language. Still for $48 \%$ of all students the knowledge of English has a conventionally symbolic value of intellectual and partially instrumental motivation. These results prove that the impact of the students' ulterior motivation is an important didactic factor in teaching skills of transnational English language communication.

\section{References}

1. O.A. Artem'eva, M.N. Makeeva, R.P. Mil'rud. Methodology of the organization of professional training of the expert on the cross-cultural communication basi. Izd-vo Tamb. gos. tehn. un-ta, 160, (2005)

2. O.A. Bashkirova. Ways of increasing the motivation of students to study a foreign language in the Technical University. Omsk Sc. Bulletin. Series Society. History. Modernity. 3, 85-88, (2018)

3. D.A. Wang. Study on Students' Integrative Motivation for College English Learning in Chinese Universities. 2nd Int. Conf. on Appl. Soc. Sc. Res, 11-13, (2014)

4. R.C. Gardner. Social Psychology and Second Language Learning: The Role of Attitudes and Motivation. London: Edward Arnold (1985).

5. M. Jin. A Case Study of Non-English Major College Students' Motivation in English Language Learning. Open J. of Mod. Ling. 4, 252-259, (2014)

6. I.A. Zimnyaya. Psychological aspects of educating the foreign language speaking. Prosveshhenie, 327, (2002)

7. A.A. Verbitskiy, N.A. Bakshaeva. Development of students' motivation in context education. Vysshaya shkola, 200, (2000).

8. M. Lamb. The motivational dimension of language teaching. Lang. teach. 50 (3), 301-346, (2017)

9. I.O. Onal. Motivation of non-language universities' students to the foreign languages studying. Novosibirsk, 140, (2007) 
10. A.A. Leont'ev. Demands, motives, emotions. Izdatelstvo, 429, (MGU 1981)

11. M.J. Benson. Attitudes and motivation towards English: a survey of Japanese Freshmen. RELC J. 2(1) (1991).

12. S.I. Kaminskaya. Forming the positive motivation to foreign language learning: autoref.diss. ped. sciences cand., 16, (2011)

13. G. Brousseau. Theory of Didactical Situations in Mathematics. Springer Neth, 306, (2002)
14. Yi Liu. Motivation and Attitude: Two important non-intelligence factors to arouse students' potentialities in learning English. Cr. Ed..5(14), 1249-1253, (2014)

15. The self-assessment grid. Common European Framework of Reference for Languages (CEFR). Council of Europe, 2018. 